\title{
Myocardial Ischemia After Orthotopic Liver Transplantation
}

\author{
Daniel A. Rubin, MD, Douglas S. Schulman, MD, Todd D. Edwards, MD, \\ Thomas E. Starzl, MD, PhD, and Edward I. Curtiss, MD
}

A hypercoagulable state exists after orthotopic Iver transplantation. This hematologic abnomat ity may predispose patients to coronary thrombosls and unstable angina. The incidence of postoperative myocandial ischemia in such patients is unknown.

Sultable electrocandlograms and clinical events of consecutive patients undergoing orthotopic liver transpiantation $(n=45)$ and major intraabdominal surgery $(n=28)$ during a 3month period at a major univercity teaching hospital and transplant center were examined rotrospectrvely. Clinical myocandial ischemia or ischemic electrocardiographic changes, or both, cccurred In 6 traneplant putients compared with no patient in the nontransplant or comparison group. In 4 of the 6 patients with dramatic electrocardlographic changes and ischemic events, coronary arteriography falled to demonotrate significant obstructive dicease. It is concluded that severe myocandial ischemia may occur in patients after orthotopic liver transplantation in the absence of significant coronary disease. A hypercoagulable state may predispose to coronary thrombosis in this setting, providing insight (and a future model for study) into the development of unstable andina.

(Am J Candiol 1994;74:53-56)

From the Department of Medicine. Division of Cardiology. and De. partment of Surgery. Transplantation Division (TES). University of Pittsburgh School of Medicine and Presbyterian University Hospital. Pitsburgh, Pennsylvania. Manuscript received May 5. 1993; revised manuscript received December 10, 1993, and accepted December 13. 4 - Address for reprints: Daniel A. Rubin. MD. Division of Cardiol0gy. Cardiac Catheterization Laboratories. Allegheny General Hospial, 320 Fisst North Avenue. Pittsburgh. Pennsylvania 15212.
$\mathrm{O}$ $f$ the many precipitants of unstable angina, ${ }^{1-7} \mathrm{re}-$ cent attention has focused on systemic thrombogenic risk factors including lipoprotein(a), ${ }^{8}$ fibrinogen,, 910 and factor VII. ${ }^{9}$ Proteins C, S, and antithrombin III, and elements of the fibrinolytic system, however, have received less attention. ${ }^{11-14}$ Their significance is documented in descriptions of patients with deficiencies in these proteins who develop venous and arterial thrombi. ${ }^{15.16} \mathrm{~A}$ hypercoagulable state caused by decreased levels of proteins $C, S$, and antithrombin III exists early after orthotopic liver transplantation and contributes to hepatic artery thrombosis, a major postoperative complication. ${ }^{17-21}$ After reperfusion of the transplanted liver, synthetic function of coagulant and anticoagulant proteins resumes at variable rates resulting in in vivo activation of clotting mechanisms. ${ }^{20}$ This hypercoagulable state may predispose to vascular thrombosis. We have observed electrocardiographic and clinical evidence of extensive myocardial ischemia in patients after orthotopic liver transplantation, raising the possibility of spontaneous coronary thrombosis.

\section{METHODS}

Study patients: Standard 12-lead electrocardiograms were retrieved from 89 consecutive patients undergoing orthotopic liver transplantation over a 3-month period. In 50 patients, both a preoperative electrocardiogram within 5 months of transplant and an electrocardiogram recorded during postoperative days 2 to 14 were available. All recorded electrocardiograms were retrievable for analysis. Patients with ST-segment and T-wave deviation at baseline $(n=2)$, and with preexisting coronary disease ( $>70 \%$ diameter narrowing) were excluded. Thus, 45 patients were included for analysis. In patients with several preoperative electrocardiograms, only the tracing closest in time to transplantation was considered. When numerous electrocardiograms were obtained postoperatively, all were reviewed.

In a comparison group of 135 consecutive patients undergoing major intraabdominal surgery-elective or emergent - over the same time period, 36 patients had electrocardiograms recorded both within a 5-month period before surgery and at any point during postoperative days 2 to 14 . Preoperatively, 7 patients manifested deviation of ST and T-wave segments as previously described and were excluded from analysis. An additional patient with polycythemia vera and a hypercoagulable state was also excluded. Patients with a history of coronary artery disease who nevertheless fulfilled these entry criteria were included. Major intraabdominal surgery consisted of cholecystectomies $(n=7)$, colectomies and hemicolectomies $(n=13)$, ureteroileostomies $(n=2)$, aortobifemoral bypasses and abdominal-aortic and tho- 
racoabdominal aneurysm repairs $(n=3)$, splenorenal shunts $(n=1)$, and biliary reconstructions $(n=2)$.

Electrocardlographle criteria: Electrocardiograms from postoperative days 2 to 14 were compared with their respective preoperative tracings. Electrocardiograms were interpreted as positive for ischemia according to $\mathrm{T}$-wave criteria defined as symmetric $\mathrm{T}$-wave inversions measuring $>0.2 \mathrm{mV} \times 0.08$ second in $\geq 2$ contiguous precordial or limb leads. Tracings were also read as positive if $>1 \mathrm{~mm}(0.1 \mathrm{mV})$ of ST depression in $\geq 2$ contiguous precordial or limb leads was noted. The TP segment was regarded as the isoelectric baseline.

Clinical assessment: Cardiac catheterization was performed in 4 of the 6 transplanted patients who demonstrated significant ST and T-wave changes. Timing of catheterization varied from 7 to 43 days after transplantation and from 0.5 to 37 days after initial electrocardiographic changes. Interpretation was performed by 3 independent angiographers unaware of each patient's clinical condition. Maximal percent stenosis varied by $<20 \%$ between observers and was thus averaged.

\section{RESULTS}

Transplanted patients tended to be younger than patients in the comparison group ( $50 \pm 12$ vs $57 \pm 18$ years; $p=0.07)$. There was no difference in gender. Similar numbers of postoperative electrocardiograms were trieved in the study and comparison groups $(2.1 \pm 1.4$ $2.2 \pm 1.1$, respectively, $p=0.45$ ). Of the 45 patients dergoing liver transplantation, 6 (nos. 1 to 6) had si nificant ischemic electrocardiographic changes (Figure 1, Table I). Of these 6 patients. 3 (nos. 3, 5, and 6) h pulmonary edema, with regional wall motion abnorm ities in patients 3 and 6 (Figure 2) documented at th time of electrocardiographic changes. Repeat evalut tions days later showed normal wall motion. Patient demonstrated ischemic electrocardiographic chang: with a marked regional wall motion abnormality echocardiography. Persantine thallium-201 imaging vealed a corresponding reversible perfusion defect. Let ventriculography performed 3 weeks later was norma Patient 1 had severe chest discomfort with ischemic ele trocardiographic changes. Patient 4 had an uncompl cated clinical course. Her follow-up ejection fraction wh normal. Patients 1, 2, 3, and 6 underwent coronary teriography. No patient exhibited $>50 \%$ narrowing of at major vessel. Findings suggestive of thrombus we found in the left anterior descending artery of patient? An increased myocardial oxygen demand, as reflected double product, was not responsible for the observed chemia since no patient was hypertensive and only 1 t tient was tachycardic at the onset of clinical deterio?
FICURE 1. Twelveload electrocar. dlograms recorded before (top) and after (bottom) liver transplantation, demonstrating dramatic Twave inversions typically seen at times of myocardial ischemia (patient 2, Table I).
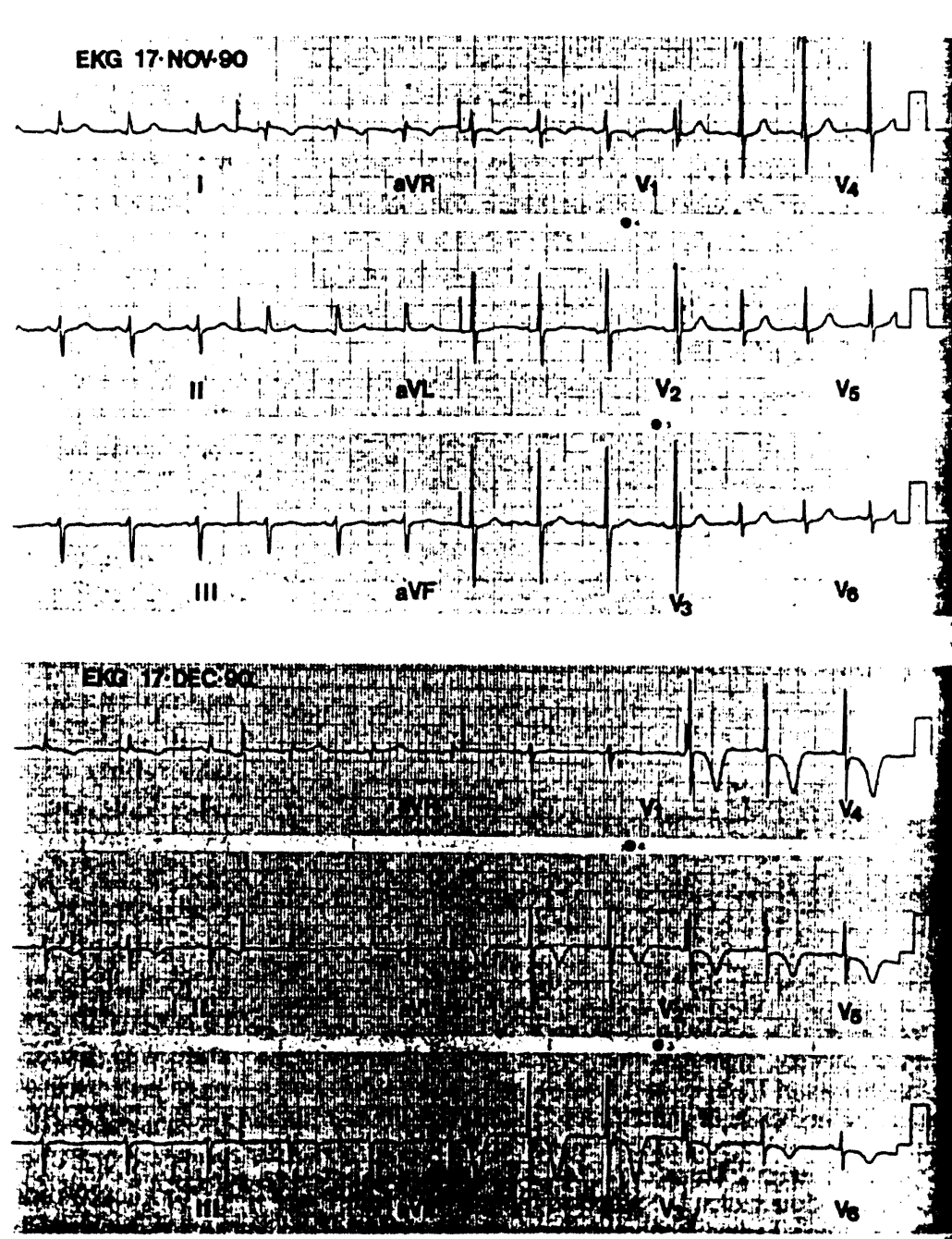

tion. No pati infarction.

Of the 28 surgery. 1 pa panied by cli tive period.

thes: hange patic..... exch baselme ST were noted.

DISCUSSIC

The same atic artery th tion may cal

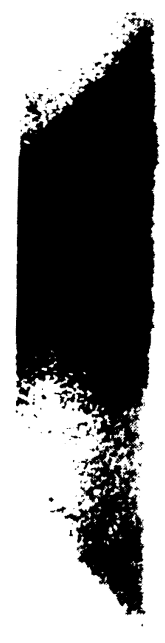

A

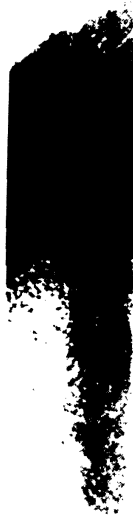

B

FGURE 2. Le and at ond-sy proje sion. It triele contrac wall motion : eal, and infor Tablo I). 
is

were re to. No No patient had enzymatic evidence of myocardial $1 \pm 1.4 \mathrm{vs}$.

atients un Of the 28 patients undergoing major intraabdominal 1) had sig. sirgery, 1 patient had precordial ST changes unaccomes (Firume of anied by clinical symptoms in the specified postoperaand 6 had 6 the period. An echocardiogram recorded at the time of abnormat $\%$ hese changes showed normal ventricular function. In tted at the patients excluded from the comparison group because of at evalua

Patient 2 ivere noted.

- changes

rmality on biscussion

naging re- 7 The same hypercoagulable state contributing to heplefect. Lefl atic artery thrombosis after orthotopic liver transplantaas normal, tion may cause myocardial ischemia and unstable aniemic lec. uncompliaction was ronary arwing of any nbus wer if patient reflected in ibserved is I only $1 \mathrm{pa}$ I dete: Iora

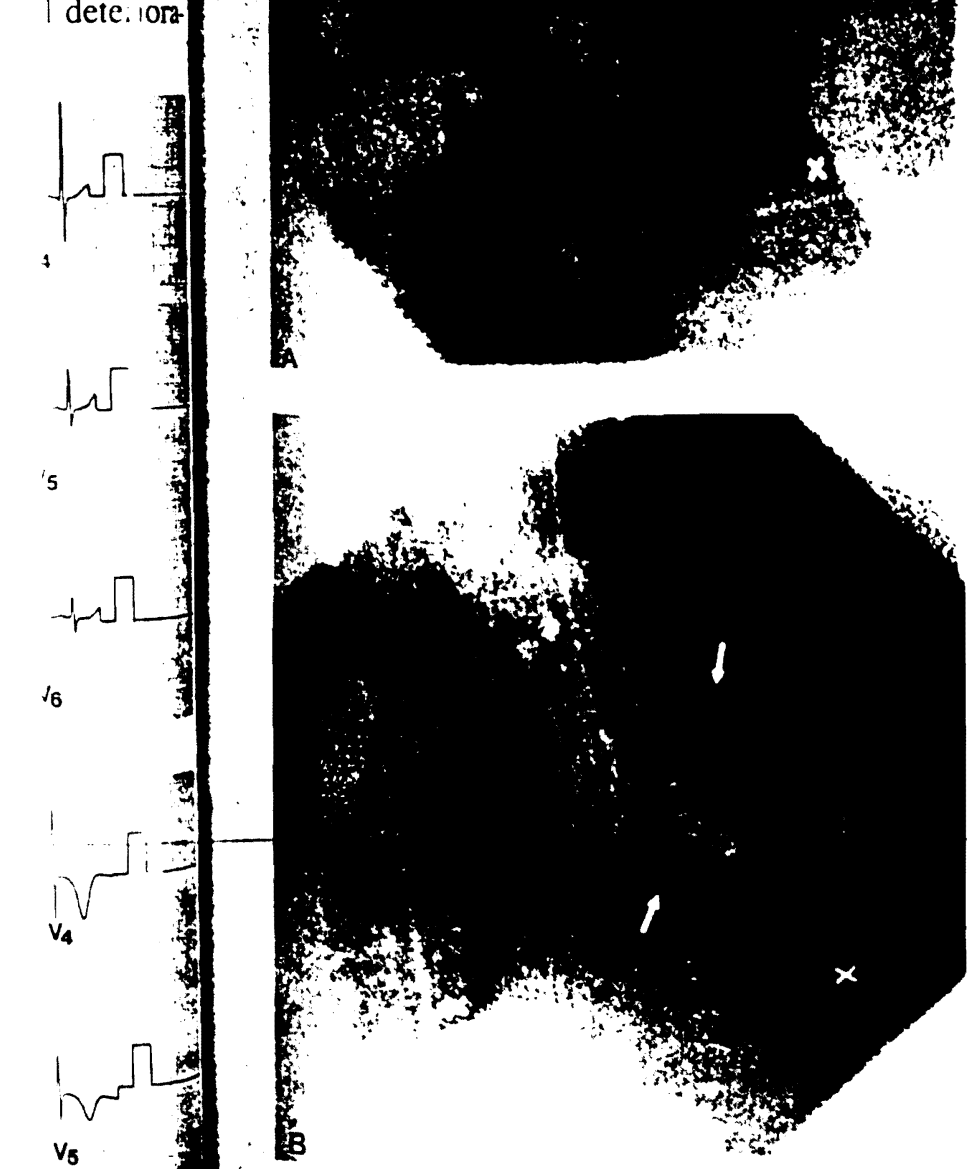

POURE 2. Loft ventricular angiogram at end-diastole (A) and at end-aystole $(B)$ in the $30^{\circ}$ right anterior oblique iclection. The basal portions (arrows) of the left ven whe contract vigorously, while an extensive regional whil motion abnormality involving the anterolateral, api$\mathrm{cl}$, and inforoapical segments is noted (pationt 3 , Inith I).

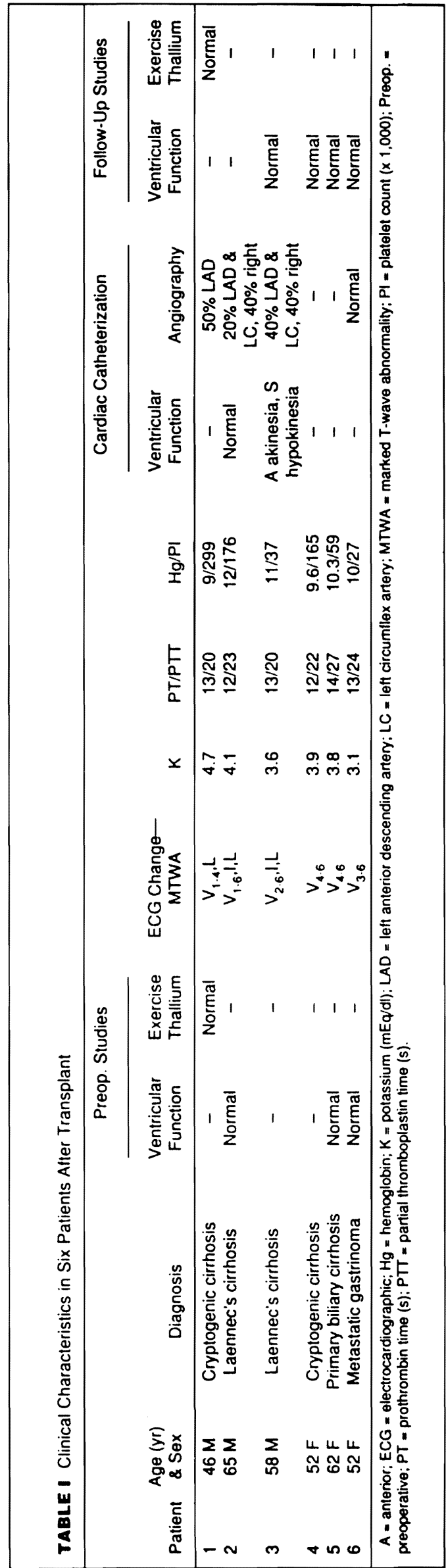


gina. In our series of consecutive liver transplant recipients, 6 of 45 patients (13\%) had ST or T-wave changes consistent with myocardial ischemia. The absence of significant underlying atherosclerotic disease and the transient nature of regional left ventricular dysfunction support a role for coronary thrombus or vasoconstriction, or both, in the observed myocardial ischemia. The finding of possible thrombus in only 1 of 4 patients undergoing angiography may be secondary to the delay in performing catheterization and spontaneous lysis.22.23

The propensity for arterial thrombosis after orthotopic liver transplantation appears highest during the first postoperative week when the discrepancy between coagulant and anticoagulant proteins is greatest. Proteins $\mathrm{C}$ and $\mathrm{S}$ remain depressed for $\geq 5$ days, and antithrombin III for $\geq 10$ days after transplantation. ${ }^{20.21}$ Evidence for activation of coagulation pathways leading toward thrombus deposition in unstable angina is provided by the increased levels of circulating and urinary markers of fibrin, fibrinopeptide $\mathrm{A}$, and other fibrin-related antigens found in patients during episodes of chest pain..$^{6.24 .25}$ Coronary vasomotion also may have contributed to the development of unstable angina in our patients. Although the clinical features in the present study do not support spasm as the predominant pathophysiologic trigger, coronary spasm need not be dismissed from the present study because it may simply be the initiating event prompting a critical narrowing whereby hemostatic and fibrinolytic mechanisms become the principal determinants of whether coronary occlusion occurs.

The findings of this study are clearly limited by their retrospective and observational nature. Patients in the comparison group had been routinely screened and treated for coronary artery disease. The development of silent ischemia was not specifically addressed. Holter monitoring may better address the prevalence of silent ischemia after operation. Nevertheless, a hypercoagulable state after orthotopic liver transplantation allows in sight into a deficient fibrinolytic system and its potential for coronary thrombosis and resulting myocardial ischemia. Deficient levels of proteins $\mathrm{C}, \mathrm{S}$, and antithrombin III likely contribute to intracoronary thrombus formation after liver transplantation. Prospective studies of anticoagulant proteins and the development of myocardial ischemia appear warranted.
1. Falk $E$. Morphologic features of unstable atherothrombotic plaques underiying acule coronary syndromes. Am J Cardiol 1989:63:114E-120E

2. Moise A. Theroux $P$. Taeymans $Y$, Descoings $B$. Lesperance J. Waters DD. Ped letier GB. Bourassa MG. Unstable angina and progressiun of coronary atherosclo rosis. N Engl J Med 1983:309:685-689.

3. Ambrose JA. Winter SL. Arora RR. Eng A. Riccio A, Gorlin R. Fuster V. An giographic evolution of coronary artery morphology in unstable angina. $J \mathrm{Am} \mathrm{Ca}^{2}$ Cardiol 1986:7:472-478.

4. Epstein SE. Talbot TL. Dynamic coronary tone in precipitation, exacerbatio and relief of angina pectoris. Am J Curdiol 1981:48:797-803.

5. Sobel M. Salzman EW. Davies GC. Handin RI. Sweeney J. Ploetz J. Kurlund C Circulating platelet products in unstable angina pectoris. Circulatton 1981:63:30 -306 6. Theroux P. Latour J. Leger-Gauthier C. Fibrinopeptide $A$ and platelet factir lex els in unstable angina pectoris. Circulation 1987:75:156-162.

7. Robertson D. Robernson RM, Nies AS, Oates JA. Friesinger GC. Variant angin pectoris: investigation of indexes of sympathetic nervous function. $\mathrm{Am} J \mathrm{Curdio}$ 1979:43:1080-1085.

8. Loscalzo J. Lipoprotein (a): a unique risk factor for atherothrombotic diseace Arteriosclerosis 1990:10:672-679.

9. Meade TW, North WRS. Chakrabarti R. Stirling Y, Haines AP. Thompson SG Haemostatic function and cardiovascular death: early results of a prospective study Luncel 1980;1:1050-1054.

10. Kannel WB. D'Agostino RB. Belanger AJ. Fibrinogen, cigarette smoking, risk of cardiovascular disease: insights from the Framingham Study. A $m$ t/eart 1987:113:1006-1010.

11. Zalewski A. Shi Y, Nardone D, Bravette B. Weinstock P. Fischman L; W son P. Goldberg S, Levin D. Bjomsson T. Evidence for reduced fibnnolytic seti ity in unstable angina at rest. Circulation 1991:83:1685-1691.

12. Esmon CT. Protein-C: biochemistry, physiology. and clinical implication Bloxd 1983:62:1155-1158.

13. Van Hinsbergh VWM. Bertina R.M. Van Wijngaarden A. Van Tilburg NT Emeis JJ. Haverkate F. Activated protein $C$ decreases plasminogen actuvator-i hibitor activity in endothelial cell-conditioned medium. Blexw 1985:65:451 14. Walker FJ. Regulation of actuvated protein $C$ by a new protein. $J$ Bul Che 1980:255:5521-5524.

15. Comp PC. Esmon CT. Recurrent venous thromboembolism in pattents with partial deficiency of protein S. N Engl J Med 1984:311:1525-1528.

16. Coiler BS. Owen J, Jesty J, Horowitz. D. Reitman MJ. Spear J. Yeh T. Con

PC. Deficiency of plasma protein S, protein C. or antichrombin III and reri thrombosis. Arteriosclerosis 1987:7:456-462.

17. Starzl TE, Marchioro TL, von Kaulla KN, Hermann G. Britaun RS. Waddell W' Hornotransplantation of the liver in humans. Surg Ginec Obstet 1903:117:659-678 18. von Kaulla KN. Kaye H. von Kaulla E. Marchioro IZ. Starzl TE. Changesi blood coagulation before and after hepatectomy or liver transplantation in dogs a man. Arch Surg 1966:92:71-79.

19. Groth CG. Changes in coagulation. In: Starzl TE, Putnam CW, eds. Expe ence in Hepatic Transplantation. Philadelphia: WB Saunders. 1969:159-175 20. Stahl RL. Duncan A. Hooks MA. Henderson JM. Millikan WJ. Warten WI A hypercoagulable state follows orthoropic liver transplantation. Hepatolisy: 19 12:553-558.

21. Flute PT, Rake MO. Williams R. Seaman MJ, Calne RY. Liver transpl: 'tati in man-IV, haemornage and thrombosis. Br Med J 1969:3:20-23.

22. Holmes DR, Harzler GO. Smith HC. Fuster V. Coronary artery thrombusis patients with unstable angina. Br Heart $J$ 1981:45:411 1 - 16 .

23. Vetrovec GW. Cowley M. Overion $\mathrm{H}$. Richardson DW. Intracoronary thro bus in syndromes of unstable myocardial ischemia. Am Heart J 1981:102:1202-12 24. Eisenberg PR. Sherman LA. Schectman K. Perez J, Sobel BE, Jalfee AS. F rinopeptide A: a marker of acute coronary thrombosis. Circulation 1985:71:912-91 25. Kruskal JB, Commertiord PJ. Franks JJ, Kirsch RE. Fibnn and tibrinogenlated antigens in patients with stable and unstable coronary anery disease. $N E$ J Med 1987:317:1361-1365. 